\title{
Microbiota characterization of a Belgian protected designation of origin cheese, Herve cheese, using metagenomic analysis
}

\author{
V. Delcenserie, ${ }^{* 1,2}$ B. Taminiau, ${ }^{* 1}$ L. Delhalle,† C. Nezer,† P. Doyen, ${ }^{*}$ S. Crevecoeur, ${ }^{*}$ D. Roussey,‡ N. Korsak, ${ }^{*}$ \\ and G. Daube* \\ ${ }^{*}$ Fundamental and Applied Research for Animal \& Health (FARAH), Food Science Department, Faculty of Veterinary Medicine, \\ University of Liège, Sart-Tilman, B43b Liège, B-4000 Belgium \\ †Quality Partner S.A., Rue Hayeneux, 624040 Herstal, Belgium \\ ¥Herve Société, Rue de Charneux, 4650 Herve, Belgium
}

\section{ABSTRACT}

Herve cheese is a Belgian soft cheese with a washed rind, and is made from raw or pasteurized milk. The specific microbiota of this cheese has never previously been fully explored and the use of raw or pasteurized milk in addition to starters is assumed to affect the microbiota of the rind and the heart. The aim of the study was to analyze the bacterial microbiota of Herve cheese using classical microbiology and a metagenomic approach based on $16 \mathrm{~S}$ ribosomal DNA pyrosequencing. Using classical microbiology, the total counts of bacteria were comparable for the 11 samples of tested raw and pasteurized milk cheeses, reaching almost 8 log $\mathrm{cfu} / \mathrm{g}$. Using the metagenomic approach, 207 different phylotypes were identified. The rind of both the raw and pasteurized milk cheeses was found to be highly diversified. However, 96.3 and $97.9 \%$ of the total microbiota of the raw milk and pasteurized cheese rind, respectively, were composed of species present in both types of cheese, such as Corynebacterium casei, Psychrobacter spp., Lactococcus lactis ssp. cremoris, Staphylococcus equorum, Vagococcus salmoninarum, and other species present at levels below 5\%. Brevibacterium linens were present at low levels ( 0.5 and $1.6 \%$, respectively) on the rind of both the raw and the pasteurized milk cheeses, even though this bacterium had been inoculated during the manufacturing process. Interestingly, Psychroflexus casei, also described as giving a red smear to Raclettetype cheese, was identified in small proportions in the composition of the rind of both the raw and pasteurized milk cheeses ( 0.17 and $0.5 \%$, respectively). In the heart of the cheeses, the common species of bacteria reached more than $99 \%$. The main species identified were Lactococcus lactis ssp. cremoris, Psychrobacter spp., and Staphylococcus equorum ssp. equorum. Interestingly, 93

Received April 15, 2014

Accepted June 18, 2014.

${ }^{1}$ These authors contributed equally to this work.

${ }^{2}$ Corresponding author: veronique.delcenserie@ulg.ac.be phylotypes were present only in the raw milk cheeses and 29 only in the pasteurized milk cheeses, showing the high diversity of the microbiota. Corynebacterium casei and Enterococcus faecalis were more prevalent in the raw milk cheeses, whereas Psychrobacter celer was present in the pasteurized milk cheeses. However, this specific microbiota represented a low proportion of the cheese microbiota. This study demonstrated that Herve cheese microbiota is rich and that pasteurized milk cheeses are microbiologically very close to raw milk cheeses, probably due to the similar manufacturing process. The characterization of the microbiota of this particular protected designation of origin cheese was useful in enabling us to gain a better knowledge of the bacteria responsible for the character of this cheese. Key words: cheese, milk, microbiota, metagenomic, $16 \mathrm{~S}$ ribosomal DNA sequencing

\section{INTRODUCTION}

Herve cheese is produced in Belgium in the area of Herve and the cheese has been awarded protected designation of origin status. The European Protected Designation of Origin is the term used to describe foodstuffs that are produced, processed, and prepared in a given geographical area using recognized know-how. Herve cheese is a soft cheese with a washed rind, and is made from raw or pasteurized milk. Its texture is firm, smooth, and creamy and it has a $45 \%$ minimum fat content. Its characteristic flavor and orange-colored rind is attributed to the presence of at least 1 bacterium: Brevibacterium linens.

The origin of this artisanal cheese dates back to the 16th century after the land in Herve area was converted into meadows. The local people used this pastureland for raising cattle and they developed dairy products that had good conservation properties.

Milk is processed into Herve cheese through various steps combining the addition of rennet, microorganisms, and salt. Briefly, after milking, batches of milk are collected and poured into tanks. The milk is curded 
after the addition of the rennet and is then cut into small pieces the size of a hazelnut. After coagulation, the curds are poured into molds to shape the cheese into a square form. The molds are turned over every few hours for $2 \mathrm{~d}$. During the ripening period, each cheese is washed individually 2 or 3 times per week with salty water or pure salts to encourage the formation of the smear.

Originally, Herve cheese was made from raw milk. Later, for safety reasons due to the potential presence of Listeria monocytogenes, Herve cheese made from pasteurized milk was developed.

The dominant microbiota present on red-smear cheeses such as Maroilles, Muenster, Limburger, and Pont l'Évêque has previously been described as being composed of gram-positive bacteria such as Micrococcus, Staphylococcus, and various coryneform species such as Corynebacterium spp., Arthrobacter spp., Rhodococcus spp., and B. linens (Brennan et al., 2002; Feurer et al., 2004b). However, the microbiota specific to Herve cheese has never previously been fully explored. The orange rind of the cheese is attributed to 1 particular bacterium: B. linens. However, as described in several studies (Brennan et al., 2002; Gori et al., 2013), contrary to accepted belief, $B$. linens is not a significant member of the surface microbiota of smear cheese.

The use of PCR-based molecular methods, such as GTG 5-PCR fingerprinting (Gori et al., 2013), denaturing gradient gel electrophoresis, temperature gradient gel electrophoresis, and terminal restriction fragment length polymorphism (Rasolofo et al., 2010), has led to better knowledge of the bacterial communities in milk and cheeses. These studies also highlighted the fact that the use of classic microbial methods gives a very limited overview of the exceptional diversity of these microbial ecosystems. The use of a metagenomic approach combined with cloning and sequencing of $16 \mathrm{~S}$ ribosomal DNA (rDNA) has already been described in milk and cheese products (Feurer et al., 2004a; Rasolofo et al., 2010). Recent advances in next-generation sequencing technologies, such as pyrosequencing, have allowed better and faster identification of microorganisms within a cheese population (Feurer et al., 2004a; Bokulich and Mills, 2012; Lusk et al., 2012).

The aim of the present study was to analyze the microbiota of raw and pasteurized milk cheeses using both classical microbiological culture methods and a metagenomic approach using pyrosequencing. This enabled us, first, to obtain a fingerprint of this microbiota; second, to establish whether original bacteria, common to both raw and pasteurized milk cheeses, were present and might play a role in the character of this cheese; and third, to ascertain whether the use of pasteurized milk significantly altered the microbiota of the cheese.

\section{MATERIALS AND METHODS}

\section{Cheese Sampling}

In total, 11 Herve cheeses were sampled and analyzed. Six cheeses were made from raw milk in 2 different artisanal factories, whereas 5 of them were made from pasteurized milk in 1 particular company. The different cheeses were either received from the company (pasteurized milk cheeses) or purchased in a grocery store from the Herve area in Belgium (raw milk cheeses). The cheeses were $41 \mathrm{~d}$ old postproduction, on average, which is slightly before the average "consumption age" of $49 \mathrm{~d}$, knowing that the expiry date is $63 \mathrm{~d}$ for this kind of cheese. The starter culture was composed of Lactococcus lactis ssp. cremoris, Lactococcus lactis ssp. lactis, Lactococcus lactis ssp. cremoris biovar diacetylactis, and Leuconostoc spp.

The hearts and rinds of the cheeses were analyzed separately (22 samples in total). The sampling was carried out from $100 \mathrm{~g}$ of cheese, cut as shown in Figure 1. For total microbiota analysis, the sample was homogenized and $25 \mathrm{~g}$ were used for analysis. Rind sampling was performed on the first $5 \mathrm{~mm}$, on each side of the cheese, including the edges. The sample was homogenized and $25 \mathrm{~g}$ was used for microbiological analysis of the rind. Heart sampling was carried out on the remaining part of the cheese without the rind at a depth of $5 \mathrm{~mm}$. That sample was homogenized and $25 \mathrm{~g}$ was used for the heart analysis.

\section{Microbiological Analysis}

Mesophilic aerobic total counts of bacteria were assessed using the method specified in NF EN ISO 4833. Plate count agar was used and plates were incubated at $30^{\circ} \mathrm{C}$ for $72 \mathrm{~h}$. Counts for lactic acid bacteria and Enterobacteriaceae were obtained using the procedures specified by the International Organization for Standardization [ISO (1998; ISO 15214) and ISO (2004; ISO

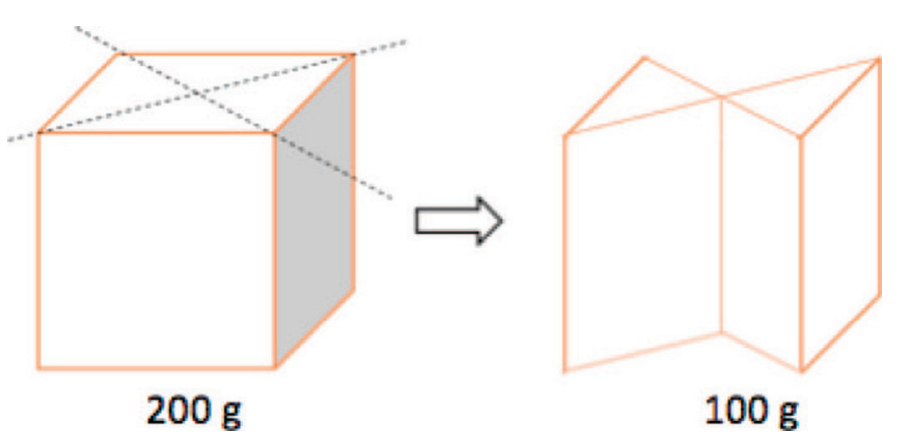

Figure 1. Illustration of the cheese sampling procedure performed in this study. Color version available in the online PDF. 
21528-2), respectively]. de Man, Rogosa, and Sharpe (MRS) and violet red bile glucose media were used with the same temperature conditions as described above, but samples on these media were incubated for 72 and $24 \mathrm{~h}$, respectively. Both rind and heart were analyzed for each of the sample categories.

\section{Total DNA Extraction}

Total DNA was isolated from each primary suspension using the DNeasy Blood \& Tissue DNA extraction kit (Qiagen Benelux B.V., Venlo, the Netherlands), following the manufacturer's recommendations. The DNA was eluted into DNase/RNase-free water and its concentration and purity were evaluated by optical density using the NanoDrop ND-1000 spectrophotometer (Isogen Life Science NV, Sint-Pieters-Leeuw, Belgium). The DNA samples were stored at $-20^{\circ} \mathrm{C}$ until use in $16 \mathrm{~S}$ rDNA amplicon pyrosequencing analysis.

\section{S rDNA Gene Library Construction and Pyrosequencing}

The 16S PCR libraries were generated for the 22 samples (11 rinds and 11 cores). The primers E9-29 and E514-530 (Brosius et al., 1981), specific to bacteria, were selected for their theoretical ability to generate the least bias of amplification capability among the various bacterial phyla (Wang and Qian, 2009). The oligonucleotide design included 454 Life Sciences A or B sequencing titanium adapters (Roche Diagnostics Belgium NV, Vilvoorde, Belgium) and multiplex identifiers fused to the $5^{\prime}$ end of each primer. The amplification mix contained $5 \mathrm{U}$ of FastStart highfidelity polymerase (Roche Diagnostics Belgium NV), $1 \times$ enzyme reaction buffer, $200 \mu M$ deoxynucleotide triphosphates (dNTP; Eurogentec SA, Liège, Belgium), $0.2 \mu M$ concentration of each primer, and $100 \mathrm{ng}$ of genomic DNA in a volume of $100 \mu \mathrm{L}$. Thermocycling conditions consisted of a denaturation step at $94^{\circ} \mathrm{C}$ for $15 \mathrm{~min}$, followed by 25 cycles of $94^{\circ} \mathrm{C}$ for $40 \mathrm{~s}, 56^{\circ} \mathrm{C}$ for $40 \mathrm{~s}, 72^{\circ} \mathrm{C}$ for $1 \mathrm{~min}$, and a final elongation step of 7 min at $72^{\circ} \mathrm{C}$. These amplifications were performed on an EP Master system gradient apparatus (Eppendorf
AG, Hamburg, Germany). The PCR products were run on a $1 \%$ agarose electrophoresis gel and the DNA fragments were extracted and purified using an SV PCR purification kit (Promega Benelux B.V., Leiden, the Netherlands). The quality and quantity of the products were assessed using a PicoGreen double-stranded DNA (dsDNA) quantitation assay (Isogen Life Science NV).

All libraries were run in the same titanium pyrosequencing reaction using Roche multiplex identifiers. All amplicons were sequenced using the Roche GS-Junior Genome Sequencer instrument (Roche Diagnostics Belgium NV).

\section{S rDNA Data Processing}

The 16S rDNA sequence reads were processed using the MOTHUR software package (Schloss et al., 2009). The quality of all the sequence reads was denoised using the PyroNoise algorithm implemented in MOTHUR and filtered according to the following criteria: minimal length of $425 \mathrm{bp}$, an exact match to the barcode, and 1 mismatch allowed to the proximal primer. The sequences were checked for the presence of chimeric amplifications using the UCHIME algorithm (Edgar et al., 2011). Table 1 summarizes the quality analysis of the metagenomic libraries.

The resultant read sets were compared with a reference data set of aligned sequences of the corresponding region derived from the SILVA database of full-length rDNA sequences (http://www.arb-silva.de/) implemented in MOTHUR (Pruesse et al., 2007). The final reads were clustered into operational taxonomic units (OTU) with the nearest neighbor algorithm using MOTHUR with a 0.03 distance unit cutoff. A taxonomic identity was attributed to each OTU by comparison with the SILVA database ( $80 \%$ homogeneity cutoff).

As MOTHUR is not dedicated to taxonomic assignment beyond the genus level, all unique sequences for each OTU were compared with the SILVA data set (version 111), using the BLASTN algorithm (https://blast.ncbi. nlm.nih.gov/Blast.cgi?PROGRAM=blastn\&PAGE_

TYPE=BlastSearch\&LINK_LOC=blasthome; Altschul et al., 1990). For each OTU, a consensus detailed taxonomic identification was given based upon the identity

Table 1. Quality analysis of the metagenomic libraries created for 22 samples of Herve cheese

\begin{tabular}{lccc}
\hline Item & $\begin{array}{c}\text { Total number } \\
(\text { or \%) }\end{array}$ & $\begin{array}{c}\text { Mean number } \\
\text { per sample }\end{array}$ & $\begin{array}{c}\text { Mean read length, } \\
\text { nucleotide }\end{array}$ \\
\hline Raw reads & 68,234 & 3,102 & 521 \\
Postdenoising/filtering & 62,218 & 2,828 & 457 \\
Loss in denoising (\%) & 8.8 & & 445 \\
Postchimeric detection & 54,115 & 2,460 & \\
Chimeric reads (\%) & 8.36 & & \\
\hline
\end{tabular}


Table 2. Results (log cfu/g; mean $\pm \mathrm{SD}$ ) of microbial counts in raw and pasteurized milk cheeses ${ }^{1}$

\begin{tabular}{|c|c|c|c|c|c|c|}
\hline Organism & \multicolumn{3}{|c|}{ Raw milk cheeses } & \multicolumn{3}{|c|}{ Pasteurized milk cheeses } \\
\hline Total bacteria & $7.82 \pm 0.47$ & $7.73 \pm 0.41$ & $7.87 \pm 0.52$ & $7.99 \pm 0.43$ & $7.50 \pm 0.38$ & $8.20 \pm 0.45$ \\
\hline Enterobacteriaceae & $3.84 \pm 2.31$ & $2.95 \pm 2.85$ & $4.73 \pm 1.30$ & $1.26 \pm 2.17$ & $0.76 \pm 1.69$ & $1.77 \pm 2.66$ \\
\hline
\end{tabular}

${ }^{1}$ No statistical difference was observed between raw and pasteurized milk cheeses.

(less than $1 \%$ of mismatches with the aligned sequence) and the metadata associated with the most frequent hits (validated bacterial species or not).

\section{S rDNA Data Analysis}

Subsampled data sets were obtained and used to evaluate the richness and microbial diversity of the samples using MOTHUR. Rarefaction curves (Colwell and Coddington, 1994), microbial biodiversity nnonparametric (NP) Shannon diversity index (Chao and Shen, 2003) and richness estimation [abundance-based coverage estimator (ACE) and Chaol estimator; Chao and Bunge, 2002]\} were calculated. The NP Shannon index gives an estimated index value for diversity and is used when undetected species are present in a sample. The ACE and Chao1 estimator are used to estimate the richness of the detected species (OTU in this case) in a sample. These estimated values can then be compared with the actual number of OTU observed in samples. The ACE index differs from the Chaol, as it takes into account the relative abundance of OTU.

\section{Statistical Analysis}

We used Welch's $t$-test to highlight statistical differences in the bacterial populations between pairs of sample categories (raw/pasteurized milk, rind/heart matrix; Rivals et al., 2007). A 2-sided Welch's $t$-test was performed and confidence intervals were calculated according to the Newcombe-Wilson method (Altenburger et al., 2002) using STAMP software (Parks and Beiko, 2010). The differences were considered significant for a corrected $P$-value of less than 0.05. All the microbiology results in this study were recorded as the means \pm the standard deviations of the results between the samples of each category.

\section{BioSample Accession Numbers}

All the BioSample sequences were deposited at the National Center for Biotechnology Information (NCBI; http://www.ncbi.nlm.nih.gov) and are available under the BioProject ID PRJNA238292.

\section{RESULTS}

\section{Microbiological Results}

All the microbiological results obtained in the study are presented in Table 2. Total counts of bacteria were comparable between both kinds of cheese, with a presence of almost $8 \mathrm{log} \mathrm{cfu} / \mathrm{g}(7.82 \pm 0.47$ and $7.99 \pm 0.43$ $\log \mathrm{cfu} / \mathrm{g}$, respectively, for raw milk and for pasteurized milk cheeses). Pasteurized milk cheeses contained the highest amount of bacteria on the rind $(8.20 \pm 0.45$ $\log \mathrm{cfu} / \mathrm{g})$ and the lowest in the heart $(7.50 \pm 0.38$ $\log \mathrm{cfu} / \mathrm{g})$. No difference between heart and rind was observed for raw milk cheeses.

Lactic acid bacteria reached more than 7 log in all cheeses $(7.54 \pm 0.59$ and $7.45 \pm 0.48 \mathrm{log} \mathrm{cfu} / \mathrm{g}$, on average, for raw milk and pasteurized milk cheeses, respectively). No difference in counts was observed between the lactic acid bacteria present in the heart or rind of pasteurized or raw milk cheeses.

Enterobacteriaceae reached more than $3 \mathrm{log} \mathrm{cfu} / \mathrm{g}$ in raw milk cheeses $(3.84 \pm 2.31 \mathrm{log} \mathrm{cfu} / \mathrm{g})$ and just more than $1 \log$ in pasteurized milk cheese $(1.26 \pm 2.17$ $\log \mathrm{cfu} / \mathrm{g})$. The rind of raw milk cheese presented the highest level of contamination $(4.73 \pm 1.30 \mathrm{log} \mathrm{cfu} / \mathrm{g})$, whereas the heart of pasteurized cheese presented the lowest counts $(0.76 \pm 1.69 \log \mathrm{cfu} / \mathrm{g})$. A high standard deviation was observed for the Enterobacteriaceae counts in pasteurized milk cheese because only 2 cheeses out of 5 were contaminated to more than $1 \log$. One was contaminated only on the rind $(2.89 \log \mathrm{cfu} / \mathrm{g})$, whereas the other was contaminated both on the rind (5.97 log $\mathrm{cfu} / \mathrm{g})$ and in the heart (3.78 $\log \mathrm{cfu} / \mathrm{g})$. Because of the high standard deviation, the observed trend could not be statistically confirmed.

\section{Establishing the Microbial Composition of Cheeses Using Metagenomic Analysis}

A total of 240 OTU was obtained and attributed to 207 phylotypes. The SILVA database allowed the identification of most $16 \mathrm{~S}$ rDNA sequences to species or at least to genus level.

Of the 207 phylotypes (Figure 2), 83 (representing more than $95 \%$ of total microbiota) were common to 
both the raw and the pasteurized milk cheeses (present in the rind or heart, or both), whereas 124 phylotypes (representing less than 5\% of total microbiota) were unique to either the raw or the pasteurized milk cheeses. Unsurprisingly, the diversity of bacteria was higher in the raw milk cheeses. Eighty-six phylotypes were specific to the raw milk cheese rind, whereas 25 were specific to the pasteurized milk cheese rind only. Seven phylotypes were specific to the raw milk cheese heart, whereas 4 were specific to the pasteurized milk cheese heart. Twenty-five phylotypes were found in the heart and rind of both kinds of cheese and these represented $90 \%$ of the relative abundance of microbial taxa found in the samples (Figure 3 ). Of these 25 core phylotypes, a few species dominated the bacterial populations. The heart of the raw milk cheeses was composed of L. lactis ssp. cremoris (79.5\%), Staphylococcus equorum (6.0\%), Psychrobacter celer (5.7\%), and Streptococcus salivarius ssp. thermophilus (4.1\%). The heart of the pasteurized milk cheeses was mainly composed of L. lactis ssp. cremoris (76.87\%), Psychrobacter sp. (11.35\%), and Staph. equorum (6.57\%).

The rind of the raw milk cheeses was mainly composed of Corynebacterium casei $(51.17 \%)$, L. lactis ssp. cremoris (11.62\%), Staph. equorum (5.54\%), Marinilactibacil- lus psychrotolerans $(4.55 \%)$, Vagococcus salmoninarum (3.16\%), Psychrobacter spp. (2.94\%), Fusobacterium spp. (2.54\%), Clostridiisalibacter (2.48\%), and Strep. salivarius (1.93\%). Many other species were present at levels below $2 \%$ and these are presented in Figure 3.

The rind of the pasteurized milk cheeses was mainly composed of species also encountered in the raw milk cheeses, such as Psychrobacter (37.76\%), L. lactis ssp. cremoris $(10.76 \%)$, C. casei $(7.42 \%)$, V. salmoninarum (5.69\%), Staph. equorum (5.28\%), Vibrio spp. (5.03\%), Fusobacterium spp. (4.39\%), M. psychrotolerans (3.69\%), Pseudoalteromonas spp. (2.71\%), Vagococcus fluvialis (2.64\%), and Strep. salivarius (2.07\%). Other species were present, including $B$. linens, but at percentages below $2 \%$ (Figure 3 ).

Although, as we have seen, 25 dominant taxa were identified across all samples, the 4 sample types (raw heart, raw rind, pasteurized heart, and pasteurized rind) were clearly characterized by different microbiota, as shown in Figure 4. A principal components (PC) analysis ((Jolliffe, 2005) revealed that biodiversity among the 4 sample categories was high. Rind and heart samples were easily separated on PC1, whereas PC2 was used to discriminate the raw milk from the pasteurized milk cheese samples.

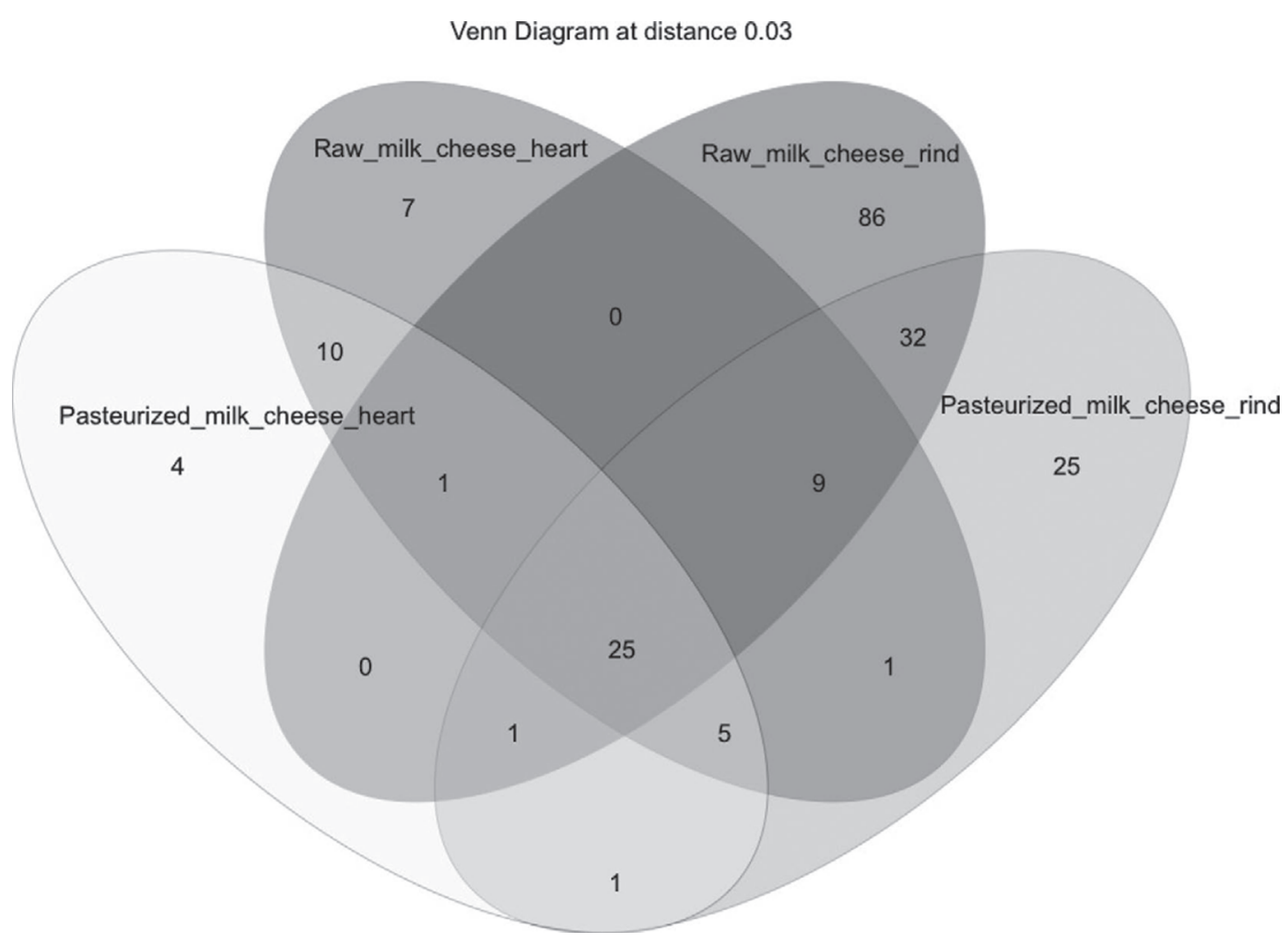

Figure 2. Venn diagram (at a 0.03 distance unit cutoff) illustrating the distribution of the 207 identified phylotypes between raw and pasteurized milk cheeses and the rinds and hearts of the samples. 


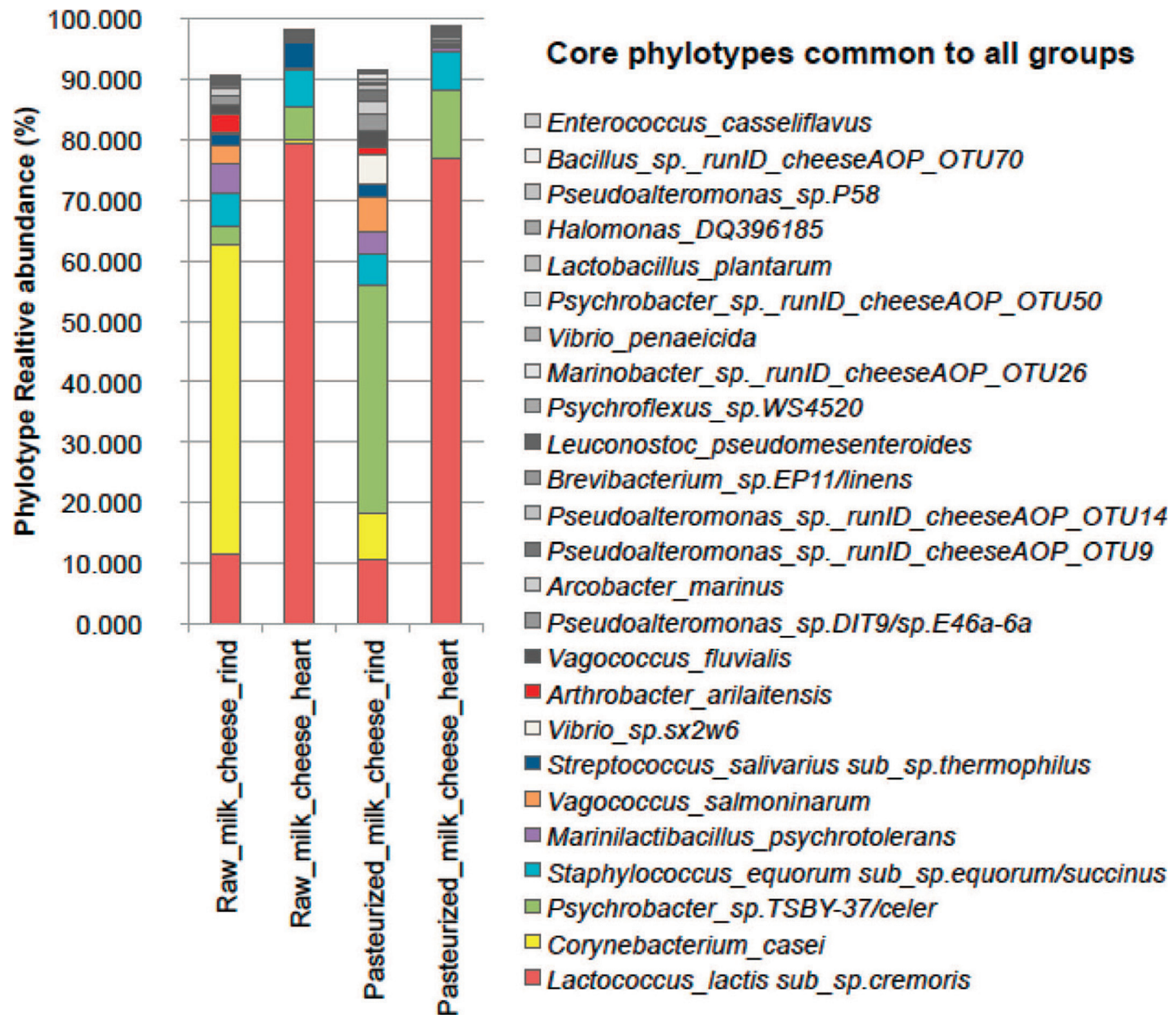

Figure 3. Bar chart detailing the relative abundance of the 25 phylotypes (to the species level) common to the 4 sample categories of cheese. Only the most abundant phylotypes are colorized.

In this way, we were able to identify a specific microbiota present only in the raw milk cheeses or in the pasteurized milk cheeses. Only a small proportion of the microbiota was found to be unique either to the raw milk or the pasteurized milk cheeses. Unique microbiota represented between $0.06 \%$ (heart of pasteurized milk cheese) and $3.5 \%$ (rind of raw milk cheese) of the total bacterial counts. The diversity was much higher in the rind and heart of the raw milk cheeses, as already described earlier. Phylotypes specifically identified in the raw milk cheese rind were mainly identified as Corynebacterium. Other phylotypes were identified as belonging to Streptococcus, Staphylococcus, or Vagococcus genera (Supplementary Figure S1; http://dx.doi. org/10.3168/jds.2014-8225). On the other hand, phylotypes specifically identified in the pasteurized milk cheese rind were Psychrobacter spp., Pseudoalteromonas spp., and Vibrio spp. (Supplementary Figure S2).

Only a few populations presented a statistically different relative abundance (Welch's $t$-test) between the raw milk and the pasteurized milk cheeses (Figure 5a). Corynebacterium casei was more present in the raw milk cheeses and this species was partially replaced by P. celer in the pasteurized milk cheeses. 


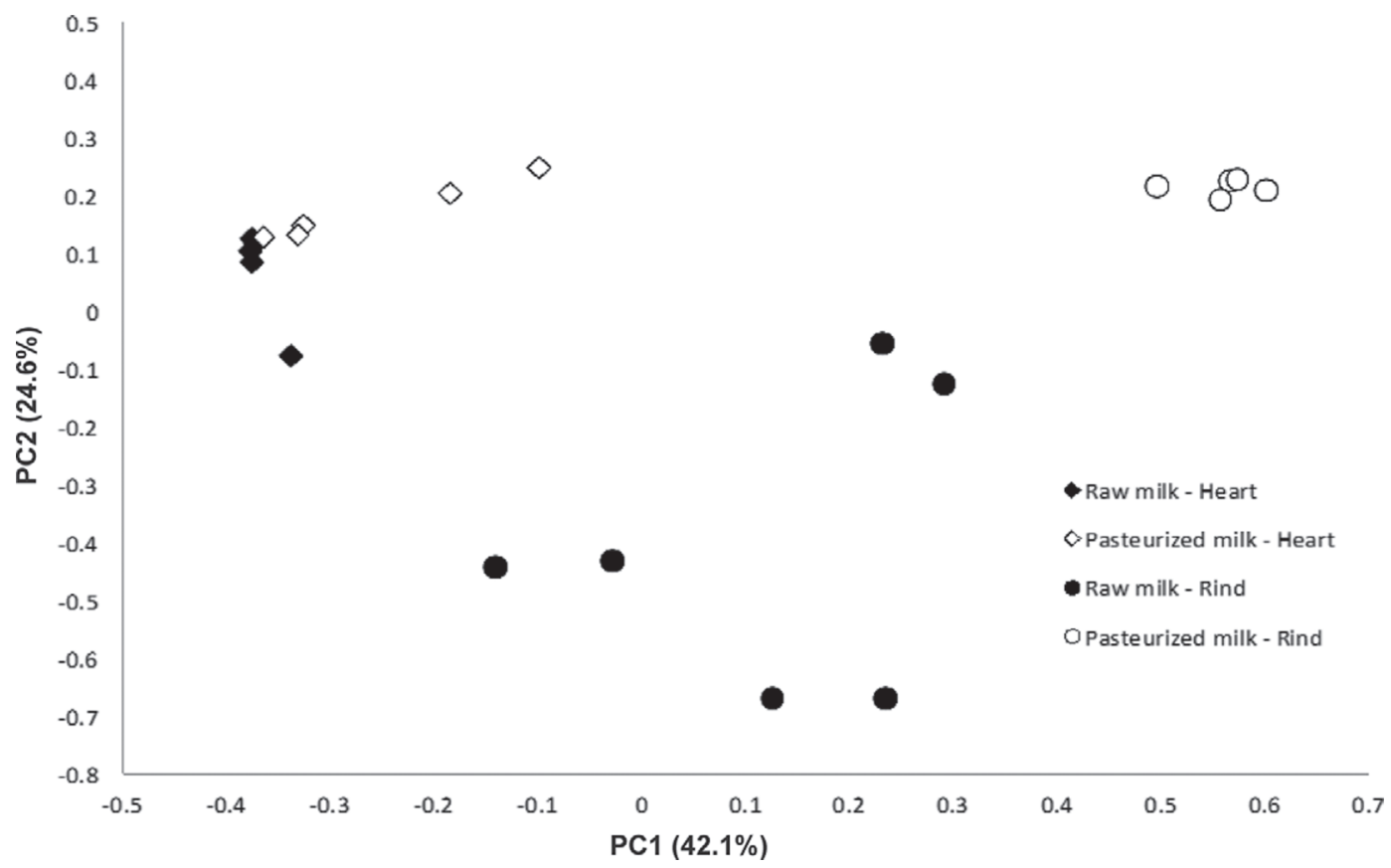

Figure 4. Analysis of the phylotype populations of the 22 samples of cheese by principal components (PC) analysis. The plot illustrates the 2 coordinates that contributed most to the variance (PC1 and PC2). The 22 samples are plotted to both axes and colorized by category (white $=$ pasteurized milk and black $=$ raw milk; circles $=$ rind matrix and diamonds $=$ heart matrix $)$.

\section{DISCUSSION}

Lactococcus lactis ssp. cremoris, widely described in cheeses (Taïbi et al., 2011), was the main species identified in the hearts of both the raw milk and the pasteur- ized milk cheeses. Lactococcus lactis ssp. cremoris and C. casei were the main species identified in the raw milk cheese rinds, whereas Psychrobacter spp., L. lactis ssp. cremoris, and $C$. case $i$ were the main species identified in the pasteurized milk cheese rinds. We also identified

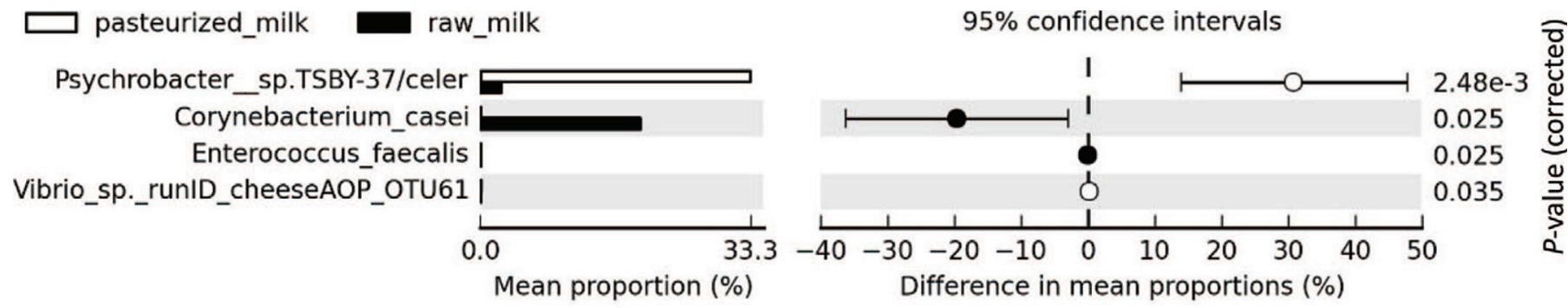

(a)

\section{pasteurized_milk}

$95 \%$ confidence intervals

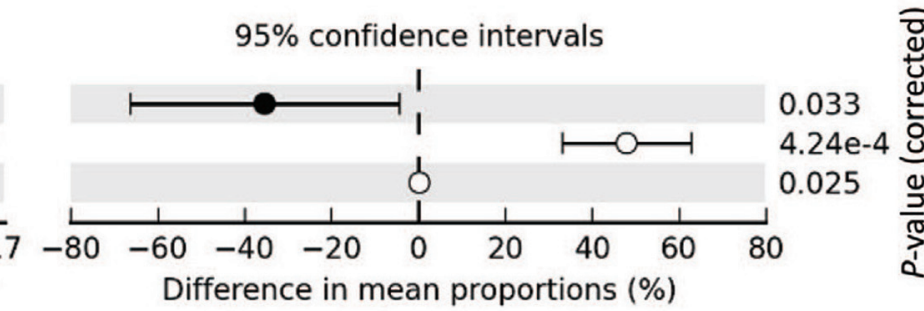

(b)

Figure 5. Extended bar plot showing the bacterial populations whose mean relative abundance differed between pasteurized milk and raw milk cheeses. The relative abundance and the difference in mean proportions are illustrated for the statistically different taxa $(P<0.05)$. The results are presented for both matrices together (a) and for the rind only (b). No statistical difference was observed for the heart matrix. 
other species, such as Staphylococcus spp., Arthrobacter spp., Brevibacterium spp., and Microbacterium spp. This was not surprising, as these species are known to be present on the rinds of similar cheeses (Brennan et al., 2002; Feurer et al., 2004a).

As shown by our PC analysis, the biodiversity of the 4 sample types (raw heart, raw rind, pasteurized heart, and pasteurized rind) was high. This underlines the fact that the use of raw or pasteurized milk had a clear effect on the microbiota present in both the heart and rind of the cheeses studied.

The bacterial populations present in the pasteurized milk cheeses were statistically different from the ones present in the raw milk cheeses. Psychrobacter celer and Vibrio spp. populations were statistically more widely encountered in the pasteurized milk cheeses $(P<0.001$ and $P<0.05$, respectively; Figure 5a), whereas $C$. casei and Enterococcus faecalis were found more in the raw milk cheeses $(P<0.05$; Figure 5a). This difference was significant in the rind of both the raw milk and the pasteurized cheeses (Figure 5b) but not in the heart. The presence of $P$. celer has already been described previously and this bacterium contributes significantly to the aromatic properties of cheese, as it influences total volatile aroma production (Irlinger et al., 2012). The presence of $P$. celer in the cheeses studied here may be explained by its presence in the saline water used in the manufacturing process. Indeed, this bacterium was originally isolated from seawater (Yoon et al., 2005). Vibrio spp. have not been reported frequently in cheese (Feurer et al., 2004a) but some studies have suggested that these bacteria could play a role in the ripening process (El-Baradei et al., 2007). Moreover, a new Vibrio species, Vibrio casei, has even been isolated from the rind of red-smear cheeses (Bleicher et al., 2010). The presence of C. casei found in the raw milk cheeses here is not surprising, as this has already been described previously (Mounier et al., 2005).

Identifying these groups of bacteria could be useful in differentiating raw from pasteurized milk cheeses. However, the use of $P$. celer as an indicator of pasteurized milk cheese should be undertaken with care. This is because its presence might be an indicator of contaminated recycled water having been used in the cheese-making process. Figure 6 shows that the fecal contaminant E. faecalis was found to be present in the raw milk cheeses $(0.6 \%)$ in the present study but that its counts were very low in the pasteurized milk cheeses (less than $0.05 \%$ ). These differences are mainly due to the nature of the milk used in raw milk cheeses, which may still be contaminated with bacteria that are either a source of typicality (C. casei and E. faecalis) or a microbiological hazard (E. faecalis). Usually, the most common enterococci encountered in cheese are

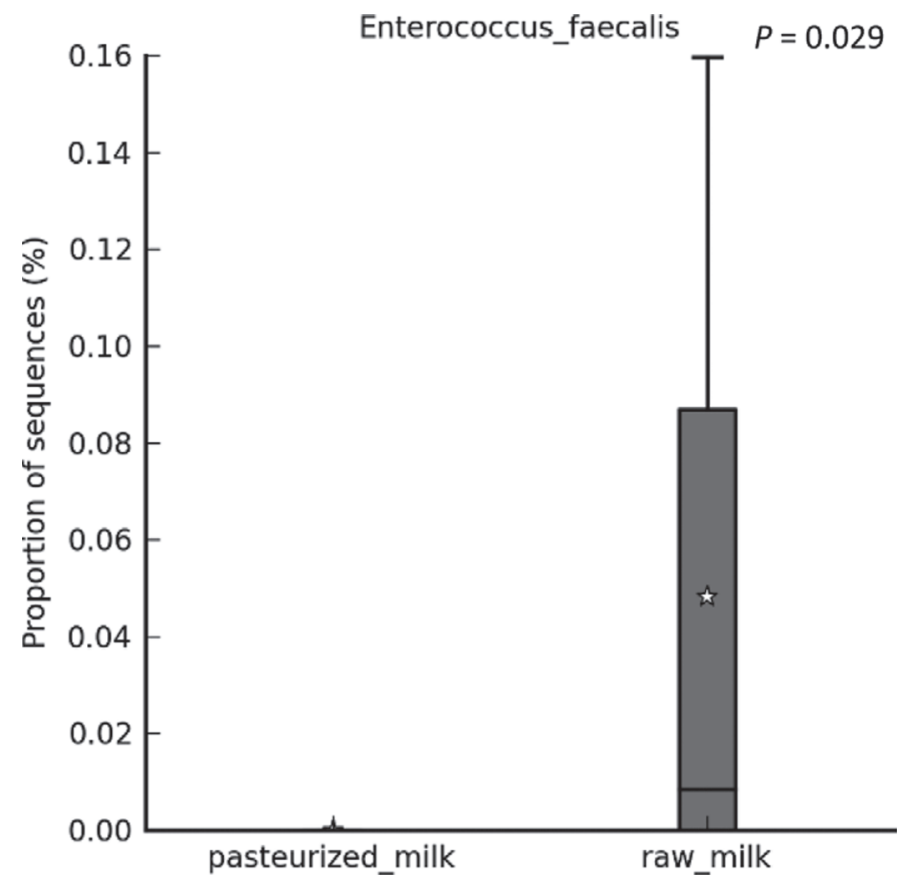

Figure 6. Box plot showing mean relative sequence abundance of Enterococcus faecalis found in pasteurized and raw milk cheeses. The star sign represents the mean value; The error bar indicates the large diversity between samples in terms of proportions of sequences.

E. faecalis and Enterococcus faecium, with E. faecium being the most frequently occurring species in dairy cows (Gelsomino et al., 2002). Indeed, E. faecium was identified in our raw milk cheese samples $(0.3 \%)$. In addition, Enterococcus casseliflavus, already previously described in cheese (Gelsomino et al., 2001, 2002), was also detected in our samples $(0.3 \%$ in raw milk cheeses and $0.1 \%$ in pasteurized milk cheeses). The suggested sources of contamination, in our case, were bulk tanks and milking machines where the presence of niches would allow the growth of those enterococci.

Other phylotypes were also identified in some of the samples in the present study, such as Vagococcus spp. Vagococcus salmoninarum, a species first identified from salmonid fishes and closely related to the Carnobacterium genus (Wallbanks et al., 1990), was identified in several of the raw milk cheese samples. Vagococcus fluvialis, previously isolated from animal and human sources (Collins et al., 1989; Pot et al., 1994; Teixeira et al., 1997) and even from cheese (Callon et al., 2014), was also identified here.

It was surprising to identify the pathogenic bacteria Morganella morganii, already previously described in milk or cheese (Tornadijo et al., 1993; Delbès-Paus et al., 2012). This bacterium, known to be able to produce biogenic amines such as histamine, has been shown to be responsible for the production of cadaverine in uncooked pressed cheeses (Delbès-Paus et al., 2012). 
Interestingly, the genus Citricoccus was also identified. This bacterium has never previously been identified in cheese, but it has been isolated several times from walls, especially mold-colonized walls (Altenburger et al., 2002; Schäfer et al., 2010). One hypothesis for the presence of Citricoccus spp. in cheese is that environmental bacteria present in industry can influence cheese composition.

In addition, the presence of halophilic and alkaliphilic lactic acid bacteria was observed in the present study, such as $M$. psychrotolerans. This bacterium, initially isolated from marine organisms in certain areas of Japan (Ishikawa et al., 2003), has already been previously described in cheese (Ishikawa et al., 2007) and is known to possess an anti-Listeria effect (Roth et al., 2011). Another bacterium identified in our study of the genus Halomonas has also been reported in smear-ripened cheeses (Mounier et al., 2005).

The identification in our samples of Pseudoalteromonas was quite unexpected, as the presence of these bacteria in cheese has previously been reported only once (Ogier et al., 2004). As described previously (Ogier et al., 2004), the presence of Pseudoalteromonas could be explained by surface cheese treatments performed during the cheese-ripening process, including washes with saline water. Brachybacterium faecium was also identified in our study. This bacterium is close to 2 other Brachybacterium species also identified once in both French Gruyere and Beaufort cheeses (Schubert et al., 1996).

Leucobacter spp., Alkalibacterium spp., Carnobacterium spp., and Raoultella planticola, already described in milk or cheese (Herbin et al., 1997; Ishikawa et al., 2007; Larpin-Laborde et al., 2011; Roth et al., 2011; Zadoks et al., 2011), were also identified in the raw milk cheeses in the current study.

One interesting genus identified in the composition of the rind of both the raw milk and the pasteurized cheeses here was Psychroflexus. A previous study reported that Psychroflexus casei gave a "red smear" color to Raclette-type cheese (Seiler et al., 2012). Our hypothesis is that, in conjunction with $B$. linens and other bacteria, this bacterium could play a role in the orange-red coloration of Herve cheese. Indeed, in the raw and pasteurized cheeses studied here, $B$. linens were not the dominant bacteria in the rind $(0.5$ and $1.6 \%$ of raw and pasteurized rind microbiota, respectively), even though these bacteria had been inoculated during the manufacturing process. This result is in agreement with previous studies reporting that $B$. linens was not a significant member of the surface microbiota of smear cheese, even though it is still used as the major component of ripening cultures (Brennan et al., 2002; Gori et al., 2013). It is also possible that other preponderant bacteria such as Psychrobacter and Staphylococcus play a role in the coloration of smear cheeses. As described previously (Hoppe-Seyler et al., 2007), the yelloworange color of the rind of these cheeses could be due to interactions between pigmented or nonpigmented B. linens and yellow-pigmented Arthrobacter (Ogier et al., 2004; Leclercq-Perlat and Spinnler, 2010). Another mechanism that has been described in the development of the color of the rind is the interaction between Arthrobacter and proteolytic bacteria in the surface microbiota (Bockelmann, 2002). One study reported the presence of Bavariicoccus seileri gen. nov., sp. nov. on the surface and in the smear water of German redsmear soft cheese (Schmidt et al., 2009). However, this bacterium was not identified in our samples. Finally, a previous study also suggested that the color of $B$. linens depended on the yeast used for the deacidification of Muenster cheese (Leclercq-Perlat et al., 2004). The presence of yeast was not, however, assessed in this study.

\section{CONCLUSIONS}

This study showed that the characterization of the microbiota of one protected designation of origin cheese, Herve, was useful in enabling us to gain a better knowledge of the bacteria responsible for the character of this cheese. The use of metagenomic analysis allowed the identification of a total of 207 different phylotypes in samples of raw or pasteurized milk Herve cheeses, showing that the biodiversity of these cheeses was high. The next step in this study would be the characterization of yeast and fungi populations. The rind of raw and pasteurized milk cheeses, in particular, was found to be highly diversified. However, in terms of proportions, more than $95 \%$ of the total microbiota was composed of species present in both kinds of cheese. This demonstrates that the pasteurized milk cheeses sampled were microbiologically very close to the raw milk cheeses. The high proportion of common microbiota could explain why the character of both kinds of cheese is so similar.

\section{ACKNOWLEDGMENTS}

The authors thank J. M. Cabay, C. Cape, and K. Boxus from the Herve Société (Herve, Belgium) for their helpful expertise and participation in the preparation of this manuscript. Our sincere thanks to Phyllis Smith from the Institut Supérieur des Langues Vivantes from the University of Liège (Liège, Belgium) for the support in English editing of the manuscript. Financial support for this project was provided by the University of Liège Special Research Funds (FOODEXP FSRC-12/60). 


\section{REFERENCES}

Altenburger, P., P. Kämpfer, P. Schumann, R. Steiner, W. Lubitz, and H.-J. Busse. 2002. Citricoccus muralis gen. nov., sp. nov., a novel actinobacterium isolated from a medieval wall painting. Int. J. Syst. Evol. Microbiol. 52:2095-2100.

Altschul, S. F., W. Gish, W. Miller, E. W. Myers, and D. J. Lipman. 1990. Basic local alignment search tool. J. Mol. Biol. 215:403-410.

Bleicher, A., K. Neuhaus, and S. Scherer. 2010. Vibrio casei sp. nov., isolated from the surfaces of two French red smear soft cheeses. Int. J. Syst. Evol. Microbiol. 60:1745-1749.

Bockelmann, W. 2002. Development of defined surface starter cultures for the ripening of smear cheeses. Int. Dairy J. 12:123-131.

Bokulich, N. A., and D. A. Mills. 2012. Next-generation approaches to the microbial ecology of food fermentations. BMB Rep. 45:377389

Brennan, N. M., A. C. Ward, T. P. Beresford, P. F. Fox, M. Goodfellow, and T. M. Cogan. 2002. Biodiversity of the bacterial flora on the surface of a smear cheese. Appl. Environ. Microbiol. 68:820830 .

Brosius, J., T. J. Dull, D. D. Sleeter, and H. F. Noller. 1981. Gene organization and primary structure of a ribosomal RNA operon from Escherichia coli. J. Mol. Biol. 148:107-127.

Callon, C., E. Retureau, R. Didienne, and M. C. Montel. 2014. Microbial biodiversity in cheese consortia and comparative Listeria growth on surfaces of uncooked pressed cheeses. Int. J. Food Microbiol. 174:98-109.

Chao, A., and J. Bunge. 2002. Estimating the number of species in a stochastic abundance model. Biometrics 58:531-539.

Chao, A., and T.-J. Shen. 2003. Nonparametric estimation of Shannon's index of diversity when there are unseen species in sample. Environ. Ecol. Stat. 10:429-443.

Collins, M. D., C. Ash, J. A. E. Farrow, S. Wallbanks, and A. M. Williams. 1989. 16S ribosomal ribonucleic acid sequence analyses of lactococci and related taxa. Description of Vagococcus fluvialis gen. nov., sp. nov. J. Appl. Bacteriol. 67:453-460.

Colwell, R. K., and J. A. Coddington. 1994. Estimating terrestrial biodiversity through extrapolation. Philos. Trans. R. Soc. Lond. B Biol. Sci. 345:101-118.

Delbès-Paus, C., S. Pochet, S. Helinck, P. Veisseire, C. Bord, A. Lebecque, M. Coton, N. Desmasures, E. Coton, F. Irlinger, and M.C. Montel. 2012. Impact of gram-negative bacteria in interaction with a complex microbial consortium on biogenic amine content and sensory characteristics of an uncooked pressed cheese. Food Microbiol. 30:74-82.

Edgar, R. C., B. J. Haas, J. C. Clemente, C. Quince, and R. Knight. 2011. UCHIME improves sensitivity and speed of chimera detection. Bioinformatics 27:2194-2200.

El-Baradei, G., A. Delacroix-Buchet, and J.-C. Ogier. 2007. Biodiversity of bacterial ecosystems in traditional Egyptian Domiati cheese. Appl. Environ. Microbiol. 73:1248-1255.

Feurer, C., F. Irlinger, H. E. Spinnler, P. Glaser, and T. Vallaeys. 2004a. Assessment of the rind microbial diversity in a farmhouseproduced vs a pasteurized industrially produced soft red-smear cheese using both cultivation and rDNA-based methods. J. Appl. Microbiol. 97:546-556.

Feurer, C., T. Vallaeys, G. Corrieu, and F. Irlinger. 2004b. Does smearing inoculum reflect the bacterial composition of the smear at the end of the ripening of a French soft, red-smear cheese? J. Dairy Sci. 87:3189-3197.

Gelsomino, R., M. Vancanneyt, T. M. Cogan, S. Condon, and J. Swings. 2002. Source of enterococci in a farmhouse raw-milk cheese. Appl. Environ. Microbiol. 68:3560-3565.

Gelsomino, R., M. Vancanneyt, S. Condon, J. Swings, and T. M. Cogan. 2001. Enterococcal diversity in the environment of an Irish Cheddar-type cheesemaking factory. Int. J. Food Microbiol. $71: 177-188$

Gori, K., M. Ryssel, N. Arneborg, and L. Jespersen. 2013. Isolation and identification of the microbiota of Danish farmhouse and industrially produced surface-ripened cheeses. Microb. Ecol. 65:602-615.
Herbin, S., F. Mathieu, F. Brulé, C. Branlant, G. Lefebvre, and A. Lebrihi. 1997. Characteristics and genetic determinants of bacteriocin activities produced by Carnobacterium piscicola $\mathrm{CP} 5$ isolated from cheese. Curr. Microbiol. 35:319-326.

Hoppe-Seyler, T.-S., B. Jaeger, W. Bockelmann, A. Geis, and K.-J. Heller. 2007. Molecular identification and differentiation of Brevibacterium species and strains. Syst. Appl. Microbiol. 30:50-57.

Irlinger, F., S. A. Y. I. Yung, A.-S. Sarthou, C. Delbès-Paus, M.C. Montel, E. Coton, M. Coton, and S. Helinck. 2012. Ecological and aromatic impact of two gram-negative bacteria (Psychrobacter celer and Hafnia alvei) inoculated as part of the whole microbial community of an experimental smear soft cheese. Int. J. Food Microbiol. 153:332-338.

Ishikawa, M., K. Kodama, H. Yasuda, A. Okamoto-Kainuma, K. Koizumi, and K. Yamasato. 2007. Presence of halophilic and alkaliphilic lactic acid bacteria in various cheeses. Lett. Appl. Microbiol. 44:308-313.

Ishikawa, M., K. Nakajima, M. Yanagi, Y. Yamamoto, and K. Yamasato. 2003. Marinilactibacillus psychrotolerans gen. nov., sp. nov., a halophilic and alkaliphilic marine lactic acid bacterium isolated from marine organisms in temperate and subtropical areas of Japan. Int. J. Syst. Evol. Microbiol. 53:711-720.

ISO (International Organization for Standardization). 1998. Microbiology of food and animal feeding stuffs-Horizontal method for the enumeration of mesophilic lactic acid bacteria - Colony-count technique at 30 degrees C. ISO 15214:1998. ISO, Geneva, Switzerland.

ISO (International Organization for Standardization). 2004. Microbiology of food and animal feeding stuffs - Horizontal methods for the detection and enumeration of Enterobacteriaceae-Part 2: Colonycount method. ISO 21528-2:2004. ISO, Geneva, Switzerland.

Jolliffe, I. 2005. Encyclopedia of Statistics in Behavioral Science. B. Everitt and D. Howell, ed. John Wiley and Sons Inc., New York, NY

Larpin-Laborde, S., M. Imran, C. Bonaïti, N. Bora, R. Gelsomino, S. Goerges, F. Irlinger, M. Goodfellow, A. C. Ward, M. Vancanneyt, J. Swings, S. Scherer, M. Guéguen, and N. Desmasures. 2011. Surface microbial consortia from Livarot, a French smear-ripened cheese. Can. J. Microbiol. 57:651-660.

Leclercq-Perlat, M. N., G. Corrieu, and H. E. Spinnler. 2004. The color of Brevibacterium linens depends on the yeast used for cheese deacidification. J. Dairy Sci. 87:1536-1544.

Leclercq-Perlat, M. N., and H. E. Spinnler. 2010. The type of cheese curds determined the colouring capacity of Brevibacterium and Arthrobacter species. J. Dairy Res. 77:287-294.

Lusk, T. S., A. R. Ottesen, J. R. White, M. W. Allard, E. W. Brown, and J. A. Kase. 2012. Characterization of microflora in Latin-style cheeses by next-generation sequencing technology. BMC Microbiol. 12:254.

Mounier, J., R. Gelsomino, S. Goerges, M. Vancanneyt, K. Vandemeulebroecke, B. Hoste, S. Scherer, J. Swings, G. F. Fitzgerald, and T. M. Cogan. 2005. Surface microflora of four smear-ripened cheeses. Appl. Environ. Microbiol. 71:6489-6500.

Ogier, J. C., V. Lafarge, V. Girard, A. Rault, V. Maladen, A. Gruss, J. Y. Leveau, and A. Delacroix-Buchet. 2004. Molecular fingerprinting of dairy microbial ecosystems by use of temporal temperature and denaturing gradient gel electrophoresis. Appl. Environ. Microbiol. 70:5628-5643.

Parks, D. H., and R. G. Beiko. 2010. Identifying biologically relevant differences between metagenomic communities. Bioinformatics $26: 715-721$.

Pot, B., L. A. Devriese, J. Hommez, C. Miry, K. Vandemeulebroecke, K. Kersters, and F. Haesebrouck. 1994. Characterization and identification of Vagococcus fluvialis strains isolated from domestic animals. J. Appl. Bacteriol. 77:362-369.

Pruesse, E., C. Quast, K. Knittel, B. M. Fuchs, W. Ludwig, J. Peplies, and F. O. Glöckner. 2007. SILVA: A comprehensive online resource for quality checked and aligned ribosomal RNA sequence data compatible with ARB. Nucleic Acids Res. 35:7188-7196.

Rasolofo, E. A., D. St-Gelais, G. LaPointe, and D. Roy. 2010. Molecular analysis of bacterial population structure and dynamics during 
cold storage of untreated and treated milk. Int. J. Food Microbiol. 138:108-118.

Rivals, I., L. Personnaz, L. Taing, and M.-C. Potier. 2007. Enrichment or depletion of a GO category within a class of genes: Which test? Bioinformatics 23:401-407.

Roth, E., S. M. Schwenninger, E. Eugster-Meier, and C. Lacroix. 2011. Facultative anaerobic halophilic and alkaliphilic bacteria isolated from a natural smear ecosystem inhibit Listeria growth in early ripening stages. Int. J. Food Microbiol. 147:26-32.

Schäfer, J., K. Martin, and P. Kämpfer. 2010. Citricoccus parietis sp. nov., isolated from a mould-colonized wall and emended description of Citricoccus alkalitolerans Li et al. 2005. Int. J. Syst. Evol. Microbiol. 60:271-274.

Schloss, P. D., S. L. Westcott, T. Ryabin, J. R. Hall, M. Hartmann, E. B. Hollister, R. A. Lesniewski, B. B. Oakley, D. H. Parks, C. J. Robinson, J. W. Sahl, B. Stres, G. G. Thallinger, D. J. Van Horn, and C. F. Weber. 2009. Introducing mothur: Open-source, platform-independent, community-supported software for describing and comparing microbial communities. Appl. Environ. Microbiol. 75:7537-7541.

Schmidt, V. S. J., R. Mayr, M. Wenning, J. Glöckner, H.-J. Busse, and S. Scherer. 2009. Bavariicoccus seileri gen. nov., sp. nov., isolated from the surface and smear water of German red smear soft cheese. Int. J. Syst. Evol. Microbiol. 59:2437-2443.

Schubert, K., W. Ludwig, N. Springer, R. M. Kroppenstedt, J.-P. Accolas, and F. Fiedler. 1996. Two coryneform bacteria isolated from the surface of French Gruyere and Beaufort cheeses are new species of the genus Brachybacterium: Brachybacterium alimentarium sp. nov. and Brachybacterium tyrofermentans sp. nov. Int. J. Syst. Bacteriol. 46:81-87.
Seiler, H., A. Bleicher, H.-J. Busse, J. Hüfner, and S. Scherer. 2012. Psychroflexus halocasei sp. nov., isolated from a microbial consortium on a cheese. Int. J. Syst. Evol. Microbiol. 62:1850-1856.

Taïbi, A., N. Dabour, M. Lamoureux, D. Roy, and G. LaPointe. 2011. Comparative transcriptome analysis of Lactococcus lactis ssp. cremoris strains under conditions simulating Cheddar cheese manufacture. Int. J. Food Microbiol. 146:263-275.

Teixeira, L. M., M. G. Carvalho, V. L. Merquior, A. G. Steigerwalt, D. J. Brenner, and R. R. Facklam. 1997. Phenotypic and genotypic characterization of Vagococcus fluvialis, including strains isolated from human sources. J. Clin. Microbiol. 35:2778-2781.

Tornadijo, E., J. M. Fresno, J. Carballo, and R. Martin-Sarmiento. 1993. Study of Enterobacteriaceae throughout the manufacturing and ripening of hard goats' cheese. J. Appl. Bacteriol. 75:240-246.

Wallbanks, S., A. J. Martinez-Murcia, J. L. Fryer, B. A. Phillips, and M. D. Collins. 1990. 16S rRNA sequence determination for members of the genus Carnobacterium and related lactic acid bacteria and description of Vagococcus salmoninarum sp. nov. Int. J. Syst. Bacteriol. 40:224-230.

Wang, Y. and P.-Y. Qian. 2009. Conservative fragments in bacterial $16 \mathrm{~S}$ rRNA genes and primer design for $16 \mathrm{~S}$ ribosomal DNA amplicons in metagenomic studies. PLoS ONE 4:e7401.

Yoon, J.-H., C.-H. Lee, S.-J. Kang, and T.-K. Oh. 2005. Psychrobacter celer sp. nov., isolated from sea water of the South Sea in Korea. Int. J. Syst. Evol. Microbiol. 55:1885-1890.

Zadoks, R. N., H. M. Griffiths, M. A. Munoz, C. Ahlstrom, G. J. Bennett, E. Thomas, and Y. H. Schukken. 2011. Sources of Klebsiella and Raoultella species on dairy farms: Be careful where you walk. J. Dairy Sci. 94:1045-1051. 